\title{
Prevalence of Irritable Bowel Syndrome in Singapore and Its Association with Dietary, Lifestyle, and Environmental Factors
}

\author{
Kewin T H Siah, ${ }^{1,2 *}$ Reuben K Wong, ${ }^{1,2}$ Yiong H Chan, ${ }^{3}$ Khek Y Ho, ${ }^{1,2}$ and Kok-Ann Gwee ${ }^{1,2}$ \\ ${ }^{I}$ Division of Gastroenterology \& Hepatology, University Medicine Cluster, National University Hospital, Singapore; ${ }^{2}$ Department of Medicine, \\ Yong Loo Lin School of Medicine, National University of Singapore, Singapore; and ${ }^{3}$ Biostatistics Unit, Yong Loo Lin School of Medicine, \\ NUHS, Singapore
}

\section{Background/Aims}

The prevalence of irritable bowel syndrome (IBS) has risen considerably over the past decade in Singapore. We aim to explore the contribution of changes in diet, lifestyle and habits that may contribute to the increased prevalence and development of IBS.

\section{Methods}

This is a survey-based cross-sectional population study aimed to gather demographic, socio-economical, lifestyle, dietary, antibiotic usage and other related information. Subjects were adult male or female Singaporeans aged 21 years or above. Association of the factors gathered with the presence or absence of IBS (by Rome III criteria) was assessed using chi-square or Fisher's exact test. Variables with a level of statistical significance of 0.1 or less in the univariate analysis were entered into a stepwise logistic regression model.

\section{Results}

A total of 297 subjects participated in the study (female 60.3\%). Overall, $20.9 \%$ subjects fulfilled the Rome III IBS criteria. Univariate analysis showed that IBS was associated with pet ownership, antibiotic usage, late dinner, (> 9 PM) and consumption of Western meals, coffee, and bread. The multivariate logistic regression analyses showed that IBS was independently associated with being a pet owner $(P=0.008 ; \mathrm{OR}, 2.5 ; 95 \% \mathrm{Cl}, 1.278-5.037)$.

\section{Conclusions}

The prevalence of IBS was $20.9 \%$ using the Rome III criteria in our study. The association between IBS and pet ownership will need further investigation.

(J Neurogastroenterol Motil 2016;22:670-676)

\section{Key Words}

Epidemiology; Irritable bowel syndrome; Pets

Received: September 17, 2015 Revised: January 21, 2016 Accepted: February 10, 2016

(c) This is an Open Access article distributed under the terms of the Creative Commons Attribution Non-Commercial License (http://creativecommons. org/licenses/by-nc/4.0) which permits unrestricted non-commercial use, distribution, and reproduction in any medium, provided the original work is properly cited.

*Correspondence: Kewin T H Siah, MD

Division of Gastroenterology \& Hepatology, NUHS Tower Block, Level 10, 1E Kent Ridge Road, Singapore 119228

Tel: +65-6779-5555, Fax: +65-6775-1518, E-mail: kewin_siah@nuhs.edu.sg 


\section{Introduction}

The gradual shift in the epidemiology of gastrointestinal diseases is a phenomenon that is presently witnessed in many parts of Asia; in particular, the prevalence of irritable bowel syndrome (IBS) has risen considerably over the past decade in Singapore. ${ }^{1-3} \mathrm{Al}$ though the etiology underpinning this disease trend is unclear, the short time span in which these changes have occurred suggests that environmental, rather than genetic, alteration is the crucial determinant. ${ }^{4,5}$ Rapid economic growth and urbanisation have transformed the environment and brought about drastic changes to the socioeconomic conditions of inhabitants. The lifestyle for many people has become sedentary, often accompanied by significant dietary changes and/or excesses. ${ }^{6-10}$ All of these factors could have directly or indirectly contributed to the shifts in the epidemiology and prevalence of gastrointestinal diseases. We aim to explore the contribution of changes in diet, lifestyle and habits that may contribute to the increased prevalence and development of IBS.

\section{Materials and Methods}

\section{Study Design}

This is a survey-based cross-sectional population study aimed to gather demographic, socio-economic, environmental, lifestyle, dietary, and other related information that may help us develop a better understanding of the current prevalence of IBS in Singapore, and factors that could play a crucial role in its etiology and epidemiology.

\section{Subjects}

The subjects were adult male or female Singaporeans aged 21 years or above who belonged to any of the 3 major ethnic groups in Singapore: Chinese, Malay, or Indian.

\section{Procedure and Methods}

We obtained from the Singapore Department of Statistics a proportional stratified sample of Chinese, Malay, and Indian households that was representative of Singapore's population. Subjects were formally invited to participate in the survey through a letter posted directly to their residential address. Those who responded to our invitation and expressed interest to participate were interviewed individually at their residence.

At the home visits, our trained field investigators further ex- plained the details of the study to the subjects. The subjects were given a chance to ask whatever questions they had. If they were agreeable after having understood the requirements of the participation, they were asked to sign an informed consent form in either English or the subjects' mother tongue (Chinese, Malay, Tamil, or Hindi). Upon obtaining formal informed consent, the investigators proceeded to interview the subjects to gather basic demographic information, as well as their body weight, height, hip, and waist dimensions to determine obesity and fat distribution. Subjects then completed a comprehensive self-administered questionnaire comprising 42 questions on their own, or if necessary, with the help of our field investigators. The investigators also collected $2-3 \mathrm{~mL}$ of the subjects' saliva to determine the presence of Helicobacter pylori infection. All measurements and collection of saliva were carried out by our trained field investigators at the subjects' residence. Principal investigators and team members were available to answer over the phone any queries the field investigators had not been able to address.

\section{Anthropometric Measurements}

All anthropometric measurements were taken with the subjects standing in an upright position with light indoor clothing, and without shoes on. Measurement of waist circumferences was taken with the subjects fully exhaled. It was made round the waist at the midpoint between the ribs and iliac crest. Hip circumference measurements were taken around the hips at the greatest horizontal circumference below the iliac crest at the level of the greater trochanter (roughly around the widest part of the hip for women, and round over the tips of the hip bones for men). Digital bathroom scales were used for measuring body weight. For consistency, the scales were calibrated in our laboratory just before the fieldwork. For height, waist and hip measurements, standard measuring tapes were used. All measurements were made in metric units, with weights measured to the nearest $0.1 \mathrm{~kg}$, and height, waist, and hip measurements to the nearest $0.5 \mathrm{~cm}$.

\section{Indices of Obesity and Fat Distribution}

For the purpose of determining the levels of obesity and body fat distribution, we used the following indices:

(1) Body mass index (BMI), defined as the ratio between weight $(\mathrm{kg})$ and the square of height $\left(\mathrm{m}^{2}\right)$.

(2) Waist circumference, defined as measurement $(\mathrm{m})$ round the waist at the midpoint between the ribs and iliac crest.

(3) Waist-hip ratio (WHR), defined as the ratio of the circumference of the waist to that of the hips: waist girth (m)/hip girth (m). 
Based on BMI, patients were graded into standard categories established by the World Health Organization with cut-off points modified for Asians. Risk-based cut-off points for waist circumference were gender-specific and as recommended for Asians by the Asian-Pacific Consensus. ${ }^{11} \mathrm{~A}$ waist circumference more than 88 $\mathrm{cm}$ in men or more than $80 \mathrm{~cm}$ in women indicates central obesity. WHR cut-offs for abdominal adiposity was set at 0.90 and 0.80 in men and women, respectively, as recommended for the Singaporean population. ${ }^{12}$

\section{Determination of Helicobacter pylori Infection}

The H. pylori infection status of the subjects was determined using a commercially available enzyme-linked immunosorbent assay for the detection of the bacteria in biological fluids. Saliva samples collected from the subjects were diluted and pre-incubated with horseradish peroxidase conjugated with anti-human immunoglobulin specific for IgG. The incubation in antibody-coated microwells facilitated the binding of the antigen present in the sample to the corresponding antibody on the surface of the microwells. After the immunological reaction, any unbound conjugate was washed off. A chromogenic substrate was then added to generate a soluble colored solution - the intensity of which was proportional to the concentration of antigen present in the sample. Concentrations were measured at 450/630 $\mathrm{nm}$ using a standard enzyme immunoassay microplate reader with the appropriate filters.

\section{Survey Questionnaire}

In brief, the questionnaire consisted of a short investigatoradministered/-assisted section to collect basic demographic and anthropometric information, and a self-administered section comprising a total of 42 questions inquiring about the individual's socioeconomic and cultural background, lifestyle, and dietary information, as well as disease-specific symptoms experienced-specifically, the presence and frequency of validated symptoms diagnostic of IBS.

The 2 parts of the questionnaire comprised the following parameters:

(1) Investigator-administered/-assisted section:
A. Demographic information
B. Anthropometric information

(2) Respondent-administered section:
A. IBS-related abdominal symptoms
B. Dyspepsia-related symptoms
C. Dietary information
D. Others (socio-economic, cultural and other information)

\section{Symptom-based Diagnostic Criteria for Diseases}

Abdominal symptoms pertaining to IBS were considered present if the individuals had experienced the symptom(s) in the preceding 6 months at a frequency of at least 3 days a month over 3 months, or approximately $10 \%$ of the time.

For symptom-based determination of the presence or absence of disease, the following diagnostic criteria was applied: a subject was classified as having symptomatic IBS if he/she had had symptoms of IBS for at least 3 months, with onset of recurrent abdominal pain or discomfort associated with 2 or more of the following at least 6 months prior to the time of survey: (1) improvement with defecation, (2) onset associated with a change in frequency of stool, and (3) onset associated with a change in form (appearance) of stool. ${ }^{13}$

\section{Dietary and Antibiotic Usage Information}

Time, location, and size of breakfast, lunch, and dinner were recorded. Dietary intakes were divided, according to frequency, into at least daily or weekly intake of standard meal portions. Subjects with prolonged or repeated antibiotic treatment 2 weeks or longer, or 2 or more courses in a year, were considered as positive antibiotic usage.

\section{Statistical Methods}

We aimed to study 500 randomly selected subjects. We determined the number of individuals who fulfilled the IBS criteria. The point prevalence of IBS was computed by taking the ratio of the number of disease cases and the total number of the population surveyed. All analyses were performed using IBM SPSS 20.0 (IBM Co, Armonk, NT, USA). Descriptive statistics for the categorical variables were reported as numeric numbers (\%). Association of the factors gathered with the presence or absence of IBS was assessed using Chi-square or Fisher's exact test. Variables with a level of statistical significance of 0.1 or less in the univariate analysis were entered into a stepwise logistic regression model. All $P$-values were two-sided with the level of significance specified at less than 0.05 .

\section{Results}

A total of 297 subjects (59.4\% response rate) participated in the study (female 60.3\%) (Table 1). Overall, 62 (20.9\%; 95\% CI, 56.5-67.5) subjects fulfilled the Rome III IBS criteria. There were $23(37 \%)$ diarrhea predominant IBS, $17(27.4 \%)$ constipation predominant IBS, 11 (17.7\%) mixed IBS, and 11 (17.7\%) unspecified IBS. Among the subjects whose age ranged between 21 and 30 
Table 1. Characteristics of Non-irritable Bowel Syndrome and Irritable Bowel Syndrome Subjects

\begin{tabular}{|c|c|c|c|}
\hline & $\begin{array}{c}\text { Non-IBS } \\
\text { n }(\%)\end{array}$ & $\begin{array}{c}\text { IBS } \\
\mathrm{n}(\%)\end{array}$ & $\begin{array}{l}\text { Total } \\
\mathrm{n}(\%)\end{array}$ \\
\hline Total & $235(79.1)$ & $62(20.9)$ & $297(100)$ \\
\hline \multicolumn{4}{|l|}{ Gender } \\
\hline Male & $96(81.4)$ & $22(18.6)$ & $118(39.7)$ \\
\hline Female & $139(77.7)$ & $40(22.3)$ & $179(60.3)$ \\
\hline \multicolumn{4}{|l|}{ Age groups } \\
\hline Age 21-30 & $47(72.3)$ & $18(27.7)$ & $65(21.9)$ \\
\hline Age $31-40$ & $61(78.2)$ & $17(21.8)$ & $78(26.3)$ \\
\hline Age 41-50 & $56(78.9)$ & $15(21.1)$ & $71(23.9)$ \\
\hline Age 51-60 & $43(81.1)$ & $10(18.9)$ & $53(17.8)$ \\
\hline Age > 60 & $28(93.3)$ & $2(6.7)$ & $30(10.1)$ \\
\hline \multicolumn{4}{|l|}{ Race } \\
\hline Chinese & $165(77.8)$ & $47(22.2)$ & $212(71.4)$ \\
\hline Malay & 25 (80.6) & $6(19.4)$ & $31(10.4)$ \\
\hline Indian & $30(93.8)$ & $2(6.3)$ & $32(10.8)$ \\
\hline Others & $15(79.1)$ & $7(31.8)$ & $22(7.4)$ \\
\hline \multicolumn{4}{|l|}{ BMI } \\
\hline$<18.5$ & $16(69.6)$ & $7(30.4)$ & $23(7.7)$ \\
\hline 18.5 to 24.9 & $145(80.1)$ & $36(19.9)$ & $181(60.9)$ \\
\hline$\geq 25.0$ & $74(79.6)$ & $19(20.4)$ & $93(31.3)$ \\
\hline \multicolumn{4}{|l|}{ Waist-hip-ratio } \\
\hline$<0.8$ & $40(76.9)$ & $12(23.1)$ & $52(17.5)$ \\
\hline 0.8 to 0.89 & $108(77.1)$ & $32(22.9)$ & $140(47.1)$ \\
\hline$\geq 0.9$ & 87 (82.9) & $18(17.1)$ & $105(35.4)$ \\
\hline Smokers & $37(80.4)$ & $9(19.6)$ & $46(15.5)$ \\
\hline H. Pylori (+) & $33(82.5)$ & $7(17.5)$ & $40(13.4)$ \\
\hline
\end{tabular}

IBS, irritable bowel syndrome; BMI, body mass index; H. pylori, Helicobacter pylori.

years old, 27.7\% had IBS — the highest prevalence among all age groups. Subjects above 60 years of age had lower prevalence of IBS compared with younger subjects (6.7 vs $22.5 \%, P=0.043$ ). The ratio of female IBS to male IBS subjects was 1.2:1. There was no significant difference in gender, race, BMI, WHR, smoking status, education, and housing types.

Univariate analysis showed that IBS was associated with pet ownership, antibiotic usage, late dinner ( $>9$ PM), and consumption of Western meals, coffee, and bread (Table 2). The multivariate logistic regression analyses showed that IBS was independently associated with being a pet owner $(P=0.008$; OR, 2.5; 95\% CI, 1.3-5.0) (Table 3).

\section{Pet Owners}

There were 78 pet owners. Thirty-one owners had furry animals such as cats, dogs, and hamsters; 8 had birds, and 21 had
Table 2. Univariate Analysis of Risk of Irritable Bowel Syndrome Showing Results with $P$-value $<0.1$

\begin{tabular}{lcc}
\hline & OR (95\% CI) & $P$-value \\
\hline Pet ownership (ever) & $2.3(1.3-4.2)$ & 0.005 \\
Non-breakfast taker & $2.7(1.3-5.8)$ & 0.008 \\
Western meal (> once/wk) & $2.1(1.2-3.6)$ & 0.012 \\
Non-coffee drinker & $2.0(1.1-3.5)$ & 0.018 \\
Bread (daily intake) & $1.9(1.0-3.6)$ & 0.035 \\
Age $<60$ & $4.1(1.0-17.5)$ & 0.043 \\
Antibiotic usage & $1.8(1.0-3.1)$ & 0.046 \\
Rice (daily intake) & $2.0(1.0-4.0)$ & 0.053 \\
Oily food (daily intake) & $2.0(1.0-3.9)$ & 0.053 \\
Single & $1.8(1.0-3.2)$ & 0.067
\end{tabular}

Table 3. Multivariate Analysis of Risk of Irritable Bowel Syndrome

\begin{tabular}{lcc}
\hline & OR $(95 \% \mathrm{CI})$ & $P$-value \\
\hline Pet ownership (ever) & $2.5(1.3-5.0)$ & 0.008 \\
Non-breakfast taker & $2.3(0.9-2.6)$ & 0.075 \\
Antibiotic usage & $1.6(0.8-3.1)$ & 0.135 \\
Non-coffee drinker & $1.5(0.8-2.8)$ & 0.252 \\
Western meal $(>$ once/wk) & $1.5(0.7-2.9)$ & 0.277 \\
Age $<60$ & $2.3(0.4-10.8)$ & 0.307 \\
\hline
\end{tabular}

Table 4. Irritable Bowel Syndrome Subtypes and Pet Ownership

\begin{tabular}{lcc}
\hline & $\begin{array}{c}\text { Non-pet owner } \\
\mathrm{n}(\%)\end{array}$ & $\begin{array}{c}\text { Pet owner } \\
\mathrm{n}(\%)\end{array}$ \\
\hline IBS-C & $10(27.0)$ & $7(28.0)$ \\
IBS-D & $13(35.1)$ & $10(40.0)$ \\
IBS-A & $7(18.9)$ & $4(16.0)$ \\
IBS-U & $7(18.9)$ & $4(16.0)$ \\
Total & 37 & 25 \\
\hline
\end{tabular}

IBS, irritable bowel syndrome; IBS-C, constipation predominant IBS; IBS-D, diarrhea predominant IBS; IBS-A, alternating IBS; IBS-U, unspecified IBS.

other pets such as tortoises and fish, etc. Eighteen subjects did not specify the type of pet(s) they had. Twenty-five (32.1\%) pet owners had IBS. Bloating was the most bothersome symptom for $30.8 \%$ of pet owners, followed by abdominal discomfort. Majority of the pet owners with IBS suffered from diarrhea-predominant subtypes (40\%) but there was no statistical difference between IBS subtypes (Table 4).

\section{Discussion}

The prevalence of IBS was $20.9 \%$ using the Rome III criteria 
in our study. IBS prevalence in Singapore was found to be $2.3 \%$ in 1998 in a study by Ho et $\mathrm{al}^{2}$ using the Manning criteria. In 2004, Gwee et $\mathrm{al}^{1}$ reported a prevalence of $8.6 \%$ in another community study using the Rome II criteria. The prevalence of IBS Rome II criteria in Asian countries were well summarized in the review by Gwee et al. ${ }^{14}$ By Rome II criteria, Taiwan had the highest prevalence for IBS, $22.1 \%$ among Asian countries. ${ }^{15}$ However, there were limited published data on the prevalence of Rome III IBS in Asia. The reported prevalence of Rome III IBS was $13.1 \%$ in Japan, ${ }^{16} 10.9 \%$ in Malaysia (Malay population) ${ }^{17}$ and $9.0 \%$ in Korea. ${ }^{18}$ The higher prevalence of IBS in Singapore compared to these countries may represent the economic success and stability achieved by Singapore for the last decades. Gwee et $\mathrm{al}^{1}$ also reported a trend of higher prevalence of IBS in affluent city states like Hong Kong and Taipei. The association of IBS with higher socio-economic status was also reported in the West. ${ }^{19,20}$

Our study shows an association between IBS and pet ownership. However, in this study the duration and period of exposure to pets was not studied. This study included all past and present pet owners. This finding is consistent with what was discovered by the Talley's group. In a study examining childhood environmental risk (less than 5 years old) and development of IBS and functional dyspepsia in Australia by Koloski et al, ${ }^{21}$ they found that pet ownership was an important risk factor for IBS and functional dyspepsia in later adult life. Interestingly, they differentiated pet categories according to their diet and showed that herbivore pets such as horses and birds were the main culprits. Koloski et $\mathrm{al}^{21}$ thought that shorter duration of breast feeding, caesarean section, and exposure to pets may increase exposure to endotoxins and alter the gut microbiota which favor the development of IBS by tilting the balance of cytokines profile towards a T helper 2 response. ${ }^{22}$

Animals like dogs and horses have been involved in animalassisted therapy in multiple chronic conditions. We often see dogs assisting people with various disabilities, and animals can also help in reduction of anxiety and depression, improvement in mood and development of social skills. ${ }^{23-26}$ Pet ownership could be a compensatory mechanism in patients suffering from IBS, perhaps due to the beneficial effects of pet-companionship on mood disorders, depression, and anxiety. ${ }^{27}$ Although we did not collect information on mood or psychological profiles in our subjects, anxiety, and mood disorders have been found to be more prevalent among patients suffering from IBS. ${ }^{28,29}$

On the other hand, pet ownership is inevitably associated with an increased exposure to animal dander. Animal dander are particles sloughed from the animal skin. Allergens from cats and dogs, such as Fel $\mathrm{d} 1$ and $\mathrm{Can} \mathrm{fl}$, can remain airborne for prolonged periods of time and attach themselves to clothing and hair. ${ }^{30,31}$ The prevalence of human allergy to pet dander has increased, due to rising public and domestic environmental exposure to pet allergens. ${ }^{32}$ Human diseases associated with sensitisation to these aeroallergens include allergic rhinitis, allergic asthma, and atopic dermatitis. There have been several reports of increased prevalence of IBS among atopic patients, especially patients with asthma. ${ }^{33-47}$ In a large primary care study of general practitioner diagnosed IBS, the odds ratio for IBS among asthma patients was 2-fold that of controls. ${ }^{47}$ Tobin et $\mathrm{al}^{33} \mathrm{re}$ ported increased mucosal mast cells in a group of IBS patients with concurrent atopic disease. Another study showed that mast cell and eosinophil concentrations in duodenal biopsies increased during the pollen season. ${ }^{48}$ This association has been termed "atopic IBS", which may represent a distinct subset of IBS. Atopic patients were also shown to have increased intestinal permeability and density of IgE-bearing mast cells. ${ }^{36}$ Sensitisation to food allergens, which were reported by patients to induce their gastrointestinal symptoms, was not shown (both via measurement of serum-specific food $\operatorname{IgE}$ and skin prick test).

However, the role of aeroallergens in causing gastrointestinal symptoms has not been fully explored. A study by Vivinus-Nebot et $\mathrm{al}^{35}$ showed that atopic IBS patients had more severe disease and diarrhea-predominant symptoms. In the same study, it was shown that IBS patients had higher sensitivity to aeroallergens compared with controls. Interestingly, Hunskar et $\mathrm{al}^{34}$ showed that in a cohort of post-Giardia infection patients, non-atopic patients were found to have increased risk of IBS after Giardia infection but the effect was not seen in atopic patients.

Our study did not find a significant dietary or obesity marker for development of IBS. There were mixed results regarding the association of IBS and obesity. There were studies that found higher IBS prevalence with increased $\mathrm{BMI},{ }^{49,50}$ and waist-circumference and visceral adipose tissue. ${ }^{51}$ Other authors cautioned regarding selection of study patients and need of a standardized assessment of obesity. ${ }^{52,53}$ Larger sample sizes may be needed to elucidate whether there was an association between BMI and IBS. Secondly, a better and more detailed dietary questionnaire with a recorded temporal relationship with symptoms should be utilised in future studies to investigate the effect of diet on IBS.

A limitation of the present study is the relative small number of participants, though the racial and weight distribution mirrored the national pattern. There is also a lack of relevant data regarding pet ownership, allergy status and psychological profiles. The relationship of pet ownership and IBS, though interesting, will need further 
in-depth investigation due to its potential implication for prevention and treatment of IBS. In future, studies should accurately document the type of pets and chronology of pet owning meticulously to produce any meaningful results. It is also important to include the allergic status and psychological profile to rule out possible confounders.

In conclusion, the prevalence of IBS was $20.9 \%$ using the Rome III criteria in our study. Our study showed that there was an association between IBS and pet ownership. This new association is interesting because it may unfold the hitherto mystery relationship between IBS and atopic diseases, especially the high prevalence of IBS seen in asthmatic patients. Whether aeroallergens, such as animal dander, house dust mites or pollen, play any role in the pathophysiology of IBS will need to be explored in future studies.

Acknowledgements: Authors thank "NUHS Medical Publications Support Unit” for writing support.

\section{Financial support: None.}

Conflicts of interest: Kok-Ann Gwee has received research grants from Abbott Laboratories and Janssen Pharmaceuticals, speaking honorarium from Abbott Laboratories, Janssen Pharmaceuticals and Boehringer Ingelheim International $\mathrm{GmbH}$, and is on the scientific advisory board of Danone Research.

Author contributions: Kewin T H Siah: planning and/or conducting the study, collecting and/or interpreting data, and/or drafting the manuscript; Reuben K Wong and Yiong $\mathrm{H}$ Chan: interpreting data, drafting the article or revising it critically for important intellectual content; and Khek Y Ho and Kok-Ann Gwee: planning and/or conducting the study, final approval of the version to be published.

\section{References}

1. Gwee KA, Wee S, Wong ML, Png DL. The prevalence, symptom characteristics, and impact of irritable bowel syndrome in an asian urban community. Am J Gastroenterol 2004;99:924-931.

2. Ho KY, Kang JY, Seow A. Prevalence of gastrointestinal symptoms in a multiracial Asian population, with particular reference to reflux-type symptoms. Am J Gastroenterol 1998;93:1816-1822.

3. Gwee KA, Siah KT, Wong RK, Wee S, Wong ML, Png DL. Prevalence of disturbed bowel functions and its association with disturbed bladder and sexual functions in the male population. J Gastroenterol Hepatol 2012;27:1738-1744.

4. Olden K, White SL. Health-related disparities: influence of environmen- tal factors. Med Clin North Am 2005;89:721-738.

5. Rappaport SM, Smith MT. Epidemiology. Environment and disease risks. Science 2010;330:460-461.

6. Dempsey PC, Owen N, Biddle SJ, Dunstan DW. Managing sedentary behavior to reduce the risk of diabetes and cardiovascular disease. Curr Diab Rep 2014;14:522.

7. Tremblay MS, Colley RC, Saunders TJ, Healy GN, Owen N. Physiological and health implications of a sedentary lifestyle. Appl Physiol Nutr Metab 2010;35:725-740.

8. Owen N, Salmon J, Koohsari MJ, Turrell G, Giles-Corti B. Sedentary behaviour and health: mapping environmental and social contexts to underpin chronic disease prevention. Br J Sports Med 2014;48:174-177.

9. Saunders TJ, Chaput JP, Tremblay MS. Sedentary behaviour as an emerging risk factor for cardiometabolic diseases in children and youth. Can J Diabetes 2014;38:53-61.

10. Dunstan DW, Howard B, Healy GN, Owen N. Too much sitting--a health hazard. Diabetes Res Clin Pract 2012;97:368-376.

11. WHO Expert Consultation. Appropriate body-mass index for Asian populations and its implications for policy and intervention strategies. Lancet 2004;363:157-163.

12. Deurenberg-Yap M, Chew SK, Lin VF, Tan BY, van Staveren WA, Deurenberg P. Relationships between indices of obesity and its comorbidities in multi-ethnic Singapore. Int J Obes Relat Metab Disord 2001;25:1554-1562.

13. Drossman DA, Dumitrascu DL. Rome III: New standard for functional gastrointestinal disorders. J Gastrointestin Liver Dis 2006;15:237-241.

14. Gwee KA, Lu CL, Ghoshal UC. Epidemiology of irritable bowel syndrome in Asia: something old, something new, something borrowed. J Gastroenterol Hepatol 2009;24:1601-1607.

15. Lu CL, Chen CY, Lang HC, et al. Current patterns of irritable bowel syndrome in Taiwan: the Rome II questionnaire on a Chinese population. Aliment Pharmacol Ther 2003;18:1159-1169.

16. Miwa H. Prevalence of irritable bowel syndrome in Japan: internet survey using Rome III criteria. Patient Prefer Adherence 2008;2:143-147.

17. Lee YY, Waid A, Tan HJ, Chua AS, Whitehead WE. Rome III survey of irritable bowel syndrome among ethnic Malays. World J Gastroenterol 2012;18:6475-6480; discussion 6479.

18. Park DW, Lee OY, Shim SG, et al. The differences in prevalence and sociodemographic characteristics of irritable bowel syndrome according to Rome II and Rome III. J Neurogastroenterol Motil 2010;16:186-193.

19. Chitkara DK, van Tilburg MA, Blois-Martin N, Whitehead WE. Early life risk factors that contribute to irritable bowel syndrome in adults: a systematic review. Am J Gastroenterol 2008;103:765-774.

20. Howell S, Talley NJ, Quine S, Poulton R. The irritable bowel syndrome has origins in the childhood socioeconomic environment. Am J Gastroenterol 2004;99:1572-1578.

21. Koloski NA, Jones M, Weltman M, et al. Identification of early environmental risk factors for irritable bowel syndrome and dyspepsia. Neurogastroenterol Motil 2015;27:1317-1325.

22. Kindt S, Van Oudenhove L, Broekaert D, et al. Immune dysfunction in patients with functional gastrointestinal disorders. Neurogastroenterol Motil 2009;21:389-398. 
23. Cirulli F, Borgi M, Berry A, Francia N, Alleva E. Animal-assisted interventions as innovative tools for mental health. Ann Ist Super Sanita 2011;47:341-348.

24. Muñoz Lasa S, Ferriero G, Brigatti E, Valero R, Franchignoni F. Animal-assisted interventions in internal and rehabilitation medicine: a review of the recent literature. Panminerva Med 2011;53:129-136.

25. Grandgeorge M, Hausberger M. Human-animal relationships: from daily life to animal-assisted therapies. Ann Ist Super Sanita 2011;47:397408.

26. Rossetti J, King C. Use of animal-assisted therapy with psychiatric patients. J Psychosoc Nurs Ment Health Serv 2010;48:44-48.

27. Beetz A, Uvnäs-Moberg K, Julius H, Kotrschal K. Psychosocial and psychophysiological effects of human-animal interactions: the possible role of oxytocin. Front Psychol 2012;3:234.

28. Solmaz M, Kavuk I, Sayar K. Psychological factors in the irritable bowel syndrome. Eur J Med Res 2003;8:549-556.

29. Mykletun A, Jacka F, Williams L, et al. Prevalence of mood and anxiety disorder in self reported irritable bowel syndrome (IBS). An epidemiological population based study of women. BMC Gastroenterol 2010;10:88.

30. Simpson A, Custovic A. Pets and the development of allergic sensitization. Curr Allergy Asthma Rep 2005;5:212-220.

31. Takkouche B, Gonzalez-Barcala FJ, Etminan M, Fitzgerlad M. Exposure to furry pets and the risk of asthma and allergic rhinitis: a metaanalysis. Allergy 2008;63:857-864.

32. Morris DO. Human allergy to environmental pet danders: a public health perspective. Vet Dermatol 2010;21:441-449.

33. Tobin MC, Moparty B, Farhadi A, DeMeo MT, Bansal PJ, Keshavarzian A. Atopic irritable bowel syndrome: a novel subgroup of irritable bowel syndrome with allergic manifestations. Ann Allergy Asthma Immunol 2008;100:49-53.

34. Hunskar GS, Langeland N, Wensaas KA, et al. The impact of atopic disease on the risk of post-infectious fatigue and irritable bowel syndrome 3 years after Giardia infection. A historic cohort study. Scand J Gastroenterol 2012;47:956-961.

35. Vivinus-Nebot M, Dainese R, Anty R, et al. Combination of allergic factors can worsen diarrheic irritable bowel syndrome: role of barrier defects and mast cells. Am J Gastroenterol 2012;107:75-81.

36. Lillest $\varnothing \mathrm{K}$, Helgeland L, Arslan Lied G, et al. Indications of 'atopic bowel' in patients with self-reported food hypersensitivity. Aliment Pharmacol Ther 2010;31:1112-1122.

37. Panicker R, Arifhodzic N, Al Ahmad M, et al. Association and symptom characteristics of irritable bowel syndrome among bronchial asthma patients in Kuwait. Ann Thorac Med 2010;5:37-42.

38. Amra B, Hoseini-Asl MK, Rahmani AR, Golshan M, MohamadZadeh Z. Correlation between asthma and irritable bowel syndrome in a general population in Iran in 2003. Respir Med 2006;100:110-114.

39. Cole JA, Rothman KJ, Cabral HJ, Zhang Y, Farraye FA. Incidence of IBS in a cohort of people with asthma. Dig Dis Sci 2007;52:329-335.

40. Roussos A, Koursarakos P, Patsopoulos D, Gerogianni I, Philippou N. Increased prevalence of irritable bowel syndrome in patients with bronchial asthma. Respir Med 2003;97:75-79.

41. Kennedy TM, Jones RH, Hungin AP, O'flanagan H, Kelly P. Irritable bowel syndrome, gastro-oesophageal reflux, and bronchial hyper-responsiveness in the general population. Gut 1998;43:770-774.

42. Jones MP, Walker MM, Ford AC, Talley NJ. The overlap of atopy and functional gastrointestinal disorders among 23,471 patients in primary care. Aliment Pharmacol Ther 2014;40:382-391.

43. Ozol D, Uz E, Bozalan R, Türkay C, Yildirim Z. Relationship between asthma and irritable bowel syndrome: role of food allergy. J Asthma 2006;43:773-775.

44. Yazar A, Atis S, Konca K, et al. Respiratory symptoms and pulmonary functional changes in patients with irritable bowel syndrome. Am J Gastroenterol 2001;96:1511-1516.

45. Huerta C, García Rodríguez LA, Wallander MA, Johansson S. Risk of irritable bowel syndrome among asthma patients. Pharmacoepidemiol Drug Saf 2002;11:31-35.

46. Sripanyakorn S, Jugdaohsingh R, Dissayabutr W, Anderson SH, Thompson RP, Powell JJ. The comparative absorption of silicon from different foods and food supplements. Br J Nutr 2009;102:825-834.

47. Powell N, Huntley B, Beech T, Knight W, Knight H, Corrigan CJ. Increased prevalence of gastrointestinal symptoms in patients with allergic disease. Postgrad Med J 2007;83:182-186.

48. Magnusson J, Lin XP, Dahlman-Höglund A, et al. Seasonal intestinal inflammation in patients with birch pollen allergy. J Allergy Clin Immunol 2003;112:45-50.

49. Le Pluart D, Sabaté JM, Bouchoucha M, Hercberg S, Benamouzig R, Julia C. Functional gastrointestinal disorders in 35,447 adults and their association with body mass index. Aliment Pharmacol Ther 2015;41:758767.

50. Phatak UP, Pashankar DS. Prevalence of functional gastrointestinal disorders in obese and overweight children. Int J Obes (Lond) 2014;38:1324-1327.

51. Lee CG, Lee JK, Kang YS, et al. Visceral abdominal obesity is associated with an increased risk of irritable bowel syndrome. Am J Gastroenterol 2015;110:310-319.

52. Pickett-Blakely O. Obesity and irritable bowel syndrome: a comprehensive review. Gastroenterol Hepatol (N Y) 2014;10:411-416.

53. Bouchoucha M, Fysekidis M, Julia C, et al. Functional Gastrointestinal Disorders in Obese Patients. The Importance of the Enrollment Source. Obes Surg 2015;25:2143-2152. 